\title{
PROPOSIÇÕES PARA ESTUDOS TERRITORIAIS ${ }^{\prime}$
}

\author{
Marcos Aurelio SAQueT ${ }^{2}$ \\ Universidade Estadual do Oeste do Paraná \\ Francisco Beltrão
}

\section{Introdução}

Nos anos 1950-60 e, principalmente, a partir da década de 1970, dá-se um processo de renovação do pensamento geográfico, em virtude de vários fatores já identificados por Dematteis (1970 e 1985) e Corrêa (1995), ocasião em que ocorre a retomada do conceito de território, que ganha centralidade em vários estudos de Geografia e mesmo em outras ciências, como a Sociologia.

Na década de 1970, no que se refere aos estudos territoriais, há marcos fundamentais neste movimento, com obras como as de G. Deleuze e F. Guattari, J. Gottmann, C. Raffestin e P. Guichonnet, V. Vagaggini e G. Dematteis, e A. Bagnasco. Porém, é nos anos 1980 e, sobretudo, a partir da década de 1990 que se expandem, no nível internacional e no Brasil, os estudos centrados no conceito de território. Destacam-se, novamente, autores como C. Raffestin, G. Dematteis, G. Deleuze, F. Guattari, A. Bagnasco, acrescidos por Robert Sack, Angelo Turco, Eugenio Turri, entre outros. E são abordagens e proposições da década de $1980 \mathrm{em}$ diante que destacamos, porque revelam muito bem esta expansão mencionada, especialmente, na Geografia.

Desde 1996 temos nos dedicado aos estudos territoriais, refletindo sobre manifestações e materializações a partir do empírico e de processos do real, de

\footnotetext{
' Este texto revela resultados da pesquisa de pós-doutorado em execução no Politécnico e Universidade de Turim (Itália), com o professor Giuseppe Dematteis e com fnanciamento da CAPES.

${ }^{2}$ Professor Adjunto no Colegiado de Geografia da Universidade Estadual do Oeste do Paraná, Campus de Francisco Beltrão; coordenador do Grupo de Estudos Territoriais (GETERR) e credenciado no Programa de Pós-Graduação em Geografia da FCT/UNESP, Campus de Presidente Prudente (mestrado e doutorado).
} 
maneira conjugada a pesquisas de caráter teórico-metodológico. Esta tarefa tem sido bastante trabalhosa, em virtude da complexidade que significa trabalhar com estas duas grandes dimensões que envolvem a pesquisa científica.

Anteriormente a este período, especialmente desde 1993, já havíamos nos dedicado a compreender a construção social do espaço geográfico, identificando e explicando desigualdades, ritmos e temporalidades de processos econômicos, como a indústria e as produções familiares, tanto agrícola como artesanal (chamadas agroindústrias familiares rurais, de pequeno porte). O conceito de espaço geográfico tinha centralidade, com o qual mostramos aspectos do processo de territorialização de forças e relações de produção nas e das atividades anteriormente citadas.

Este trabalho dos últimos dez anos se justifica pela importância que temos percebido, no que se refere, sucintamente, a duas grandes questões: a) conhecemos muito pouco os clássicos que substantivaram as bases da re-elaboração da ciência geográfica e da retomada do conceito de território a partir dos anos 1950-60 e, b) nossos procedimentos metodológicos, centrados no conceito de território, são limitados para apreender aspectos do real. No Brasil, há estudos e proposições de qualidade, como os de Santos (1988), Ianni (1992), Haesbaert (1995, 1997, 2002, 2004 e 2004a), Souza (1995), entre outros, incluindo os nossos (SAQUET 2000, 2001/2003, 2004 e 2006), porém, como temos encontrado uma certa abundância de referências na literatura italiana, dedicamo-nos a estudá-la, mais detidamente, desde 1999.

Desse modo, neste texto, enfatizamos, além do geógrafo bem conhecido e referenciado no Brasil, Claude Raffestin, as contribuições de três geógrafos italianos: Giuseppe Dematteis, Angelo Turco e Eugenio Turri - todos com muitos anos de dedicação aos estudos territoriais. A menção a Raffestin se justifica pela interrelação de seus estudos com geógrafos italianos, especialmente com Giuseppe Dematteis e Angelo Turco. Acredito que este trabalho demonstrará esta afirmação.

Essa ênfase é fundamental, porque a Geografia italiana é muito pouco difundida e conhecida no Brasil. Por isto, trata-se de um trabalho inédito, no estudo e divulgação de autores, obras e abordagens das Ciências Sociais italianas (como já realizado em Saquet, 2001/2003, 2004, 2004a, 2005, 2005a e 2006), especialmente em relação aos pioneiros em abordagens renovadas do conceito de território, como Bagnasco (1977 e 1988), Vagaggini e Dematteis (1976) e Dematteis (1963, 1970, 1985, 1995), entre outros.

No final do trabalho realizamos algumas considerações teórico-metodológicas com base nos referidos autores e em nossas próprias reflexões sobre a formação de territórios, centrados na dinâmica socioespacial de temporalidades e territorialidades. 


\section{Aspectos da contribuição materialista de Claude Raffestin}

Raffestin (1980/1981/1993), um dos estudiosos que tem influenciado consideravelmente a Geografia no Brasil, ao que parece, marca a expansão dos estudos territoriais que se efetivam a partir dos anos 1980 e, principalmente, da década de 1990. Claude Raffestin destaca o caráter político do território. Após fazer uma reflexão crítica sobre concepções de poder centradas na atuação do Estado, propugna, tendo como uma de suas principais referências Michel Foucault, em favor de distintas variantes do poder, para além da atuação do Estado. O poder está presente nas ações do Estado, mas também de instituições, empresas..., enfim, nas relações sociais que se efetivam na vida cotidiana, visando o controle e a dominação sobre os homens e as coisas.

Ao mesmo tempo, referenciando-se em Henri Lefebvre, afirma que o território é um espaço modificado pelo trabalho e revela relações de poder. Alerta também para os signos da vida cotidiana: "Do Estado ao indivíduo, passando por todas as organizações pequenas ou grandes, encontram-se atores sintagmáticos que 'produzem' o território. (...) Em graus diversos, em momentos diferentes e em lugares variados, somos todos atores sintagmáticos que produzem 'territórios'." (RAFFESTIN, 1993:152).

O território, desta maneira, é objetivado por relações sociais, de poder e dominação, o que implica a cristalização de uma territorialidade, ou de territorialidades, no espaço, a partir de diferentes atividades. Isso, de acordo com Raffestin, assentase na construção de malhas, nós e redes, delimitando campos de ações, de poder, nas práticas espaciais queconstituem o território.

Um aspecto quase negligenciado nas abordagens referentes à contribuição de Raffestin (1993), é justamente o que denomina de sistema territorial, resultado das relações de poder do Estado, das empresas e outras organizações e dos indivíduos. Referenciando-se em Gottmann (1973) e Soja (1971), afirma que, historicamente, os atores sociais efetuam a repartição da superfície terrestre, a implantação de nós e a construção de redes.

Estes atores produzem as tessituras, mais ou menos delimitáveis, e territorialidades que se inscrevem nas dinâmicas políticas, econômicas e culturais: "(...) o próprio sistema sêmico é marcado por toda uma infra-estrutura, pelas forças de trabalho e pelas relações de produção, em suma, pelos modos de produção". (RAFFESTIN, 1993:144) Embora trate de delimitações, reconhece e indica uma transposição dos limites políticos e administrativos através de atividades econômicas e de vias e meios de circulação e comunicação. As redes têm centralidade em sua proposta de abordagem territorial, compreendidas através da complementaridade existente entre a circulação e a comunicação, como fluxos materiais e imateriais, na produção do território.

Há indícios para uma articulação das distintas dimensões sociais, substantivando uma postura múltipla frente ao território e à territorialidade, entre as dimensões da 
economia, política e cultura, simultaneamente. As próprias representações do espaço, conforme Raffestin, significam controle, domínio e revelam a imagem do território.

Uma limitação da abordagem de Raffestin (1993), está na sua compreensão do conceito de espaço geográfico. Entende o espaço como substrato, como palco, pré-existente ao território: "A matéria (ou substância), encontrando-se na superfície da terra ou acessível a partir dela, é assimilável a um 'dado', pois preexiste a toda ação humana. Nesse sentido, ela equivale ao espaço (...)." (RAFFESTIN, 1993:223). Tem um conceito superficial, enquanto natureza-superfície, recursos naturais. No entanto, as contribuições de Claude Raffestin aos estudos geográficos do território são inegáveis.

Uma discussão tratada por Raffestin (1993) e importante para nossa reflexão, relaciona-se à consideração da natureza (recursos naturais) como elemento presente no território. Este autor sinaliza para esta questão, enfatizando o uso e transformação dos recursos naturais como instrumentos de poder: "A dimensão de uma malha nunca é - ou quase nunca - aleatória, pois cristaliza todo um conjunto de fatores, dos quais uns são físicos, outros humanos: econômicos, políticos, sociais e/ou culturais" (RAFFESTIN, 1993:155).

Enfim, sumariamente, entende o território e a territorialidade como multidimensionais e inerentes à vida em sociedade. $\mathrm{O}$ homem vive relações sociais, a construção do território, interações e relações de poder; diferentes atividades cotidianas, que se assentam na construção de malhas, nós e redes. A territorialidade se manifesta em distintas escalas espaciais e sociais e varia no tempo.

De fato, as relações de poder são um componente indispensável na efetivação de um território: "O campo da relação é um campo de poder que organiza os elementos e as configurações" (RAFFESTIN, 1993:53). E são estas relações que cristalizam o território e as territorialidades: "O território (...) é a cena do poder e o lugar de todas as relações (...)" (1993:58). O território é um lugar de relações a partir da apropriação e produção do espaço geográfico. Como o próprio Raffestin (1993) afirma, apesar de estarem sempre presentes, as tessituras, nós e redes, ou, os elementos e fatores constituintes do território, podem ser diferentes de uma sociedade para outra. O que muda e/ou permanece, para cada período e/ou momento e lugar, é o arranjo social, espacial e territorial.

Outra contribuição fundamental de Claude Raffestin, em outra obra (1984), diz respeito ao que denomina de processo TDR, que se dá, para o autor, em virtude de fatores, principalmente, econômicos. Principalmente, porque, para Raffestin (1984), o próprio mercado é um lugar de emissão de símbolos, sinais, códices. Estes estão presentes na dinâmica econômica, nas informações e comunicações, nos preços. O processo de TDR (territorialização, desterritorialização e reterritorialização) gera um espaço temporalizado em razão destas informações que circulam e comunicam, interligando diferentes atores sociais.

Desta maneira, a territorialização, para este geógrafo, é um processo de relações sociais, de perda e reconstrução de relações. Se a desterritorialização, para o autor, 
significa a perda do território, de limites e fronteiras, significa que Raffestin, nesta abordagem, compreende o território com limites e fronteiras, possivelmente, definidos pela atuação do Estado. De qualquer forma, orienta a abordagem para a contemplação da re-territorialização no nível material, reflexão efetivada anteriormente, no plano epistemológico, por G. Deleuze e F. Guattari.

Com isto, fica claro o caráter relacional de sua argumentação: relações de poder, redes de circulação e comunicação, territorialidades, dominação de recursos naturais, entre outros componentes que indicam relações sociais entre sujeitos e entre estes com seu lugar de vida, tanto econômica como política e culturalmente.

\section{A abordagem materialista de Giuseppe Dematteis}

Giuseppe Dematteis é um dos geógrafos que tem construído a chamada renovação da ciência geográfica. É um estudioso incansável, entre outros, em favor das causas da Geografia. Entre suas dezenas de estudos publicados desde os anos 1960, escolhemos uma obra que se considera clássica e referência obrigatória ao se tratar da história da Geografia, do conceito de território e de procedimentos para sua compreensão, Le metafore della Terra, publicada em 1985. Como já abordamos em Saquet (2004) aspectos de sua argumentação no livro intitulado Progetto Implicito (1995), agora evidenciaremos também um texto de 2001, porque Giuseppe Dematteis resume muito bem, aí, sua proposta de abordagem do território e da territorialidade.

Antes disso, porém, é importante ressaltar sua preocupação, manifestadamente numa obra de 1970, com a necessidade de superação da dicotomia Geografia Física versus Geografia Humana e Geografia neopositivista (teorético-quantitativa) versus Geografia humanística, quando propugna em favor de uma abordagem históricocrítica. Já neste momento, neste texto, compreende o território como produto social, isto é, ele significa uma complexa combinação, particular, de relações terrritoriais, horizontais (entre pessoas, na produção, circulação...) e verticais (clima, solo, tipos de cultura...). Dematteis reconhece, desta maneira, a complexidade dos problemas territoriais, inerentes à coexistência de fatos heterogêneos, ou seja, de desigualdades que se combinam territorialmente. Ao mesmo tempo, na formação de um certo território, também considera os componentes naturais influenciando em processos sociais. Sinaliza, sucintamente, para uma abordagem relacional e múltipla do território, contemplando aspectos da sociedade e da natureza, o que detalha e aprofunda posteriormente, principalmente, a partir dos anos 1980.

Para Dematteis (1985), na Terra há um processo de apropriação que pressupõe uma complexa combinação de fatos sociais, técnicos, culturais, econômicos e políticos que correspondem às condições territoriais inerentes a um conjunto de lugares e inter-relações entre estes lugares. Desta maneira, ele define alguns dos principais traços de sua abordagem e conceito de território, centrada nas dimensões 
sociais: nas dinâmicas da economia, da política e da cultura. Compreende o território como campo de domínio, de controle, efetivado tanto por grandes multinacionais como pela Igreja Católica, por grupos políticos e por pequenos supermercados. É produto de relações de poder, lembrando a concepção de Raffestin (1980/1981). Outros autores importantes para sua reflexão, são Jean Gottmann e Eugenio Turri.

Para Dematteis (1985), o território da sociedade humana, isto é, como produto da socialização, é completamente diverso da compreensão (imprópria) do território como fruto do comportamento animal. $\mathrm{O}$ território é fundado em comportamentos opostos, envolvendo a comunicação, a cooperação e a troca, ou seja, as formas de socialização em uma dada formação territorial. Em sua abordagem do território, considera as superações (mudanças), as contradições e a processualidade histórica: "Na história dos homens a superação (...) sempre foi fonte de contradições, tensões, conflitos internos, crises e mudanças: e esta é uma característica fundamental de nosso conceito de território, não verificada na territorialidade animal" (DEMATTEIS, 1985:74). O território não indica uma realidade natural. Para isto, utiliza o conceito de Terra. O território significa uma realidade material e técnica.

Faz uma abordagem claramente materialista do conceito de território: "A Terra é tornada território quando há comunicação, quando é meio e objeto de trabalho, de produção, de trocas, de cooperação" (1985:74). O território é um produto socioespacial, de relações sociais que são econômicas, políticas e culturais e de ligações, de redes internas e externas que envolvem a natureza: "Por esta via o espaço físico entra nas relações e nas estruturas sociais" (1985:75). O Estado e o mercado têm centralidade em sua concepção.

Um aspecto importante é que a abordagem de Dematteis lembra a de Raffestin (1980/1981) ao tratar da relação espaço versus território, porém, não separa estes conceitos e processos, nem entende o espaço geográfico apenas como substrato (palco) de relações sociais. Giuseppe Dematteis compreende o território ligado ao que denomina de espaço-ambiente material modelado pelas forças políticas e de mercado e não como duas instâncias separadas em níveis distintos. Sucintamente: “O território na sua essência não é nem máquina, nem capital. É o seu contrário. É o lugar onde se demonstra a prioridade do político a respeito do econômico, onde o capital necessita ser destruído (...) para poder se reproduzir, onde a concorrência deve necessariamente substituir a cooperação (...)" (DEMATTEIS, 1985:80). No seu entendimento, não há território sem uma trama de relações sociais. Nesta trama, há interações entre a Terra e o território, sendo que isto revela a centralidade do conceito de território para este geógrafo italiano:

A geografia não é a representação da Terra, mas das estruturas materiais da socialização (comunicação-produção), isto é, do território. O espaço geográfico (...) é um meio com o qual representamos as nossas relações com o resto da sociedade e do 
mundo, dando-lhe um significado (...) em termos de territorialidade, como forma particular de experiência que nos permite identificamonos, em uma trama de relações (...). (DEMATTEIS, 1985:98).

Espaço e território são seus conceitos principais e não estão separados em sua concepção de Geografia, na qual é basilar a utilização de metáforas. A geografia é sumariamente entendida como uma maneira de representação do território através de metáforas. Desta forma, é possível ver o território e representá-lo através de imagens que podem ser compreendidas como paisagens. O espaço geográfico também é uma metáfora de relações territoriais: “(...) a concepção metafórica permite explicar de modo não metafísico o problema fundamental e nunca resolvido na Geografia científica moderna: aquele da relação entre Terra e sociedade humana" (Idem, p. 135).

É uma forma de se trabalhar, na Geografia, a interação Terra-território, através da representação e do estudo da vida cotidiana, na qual é possível se apreender a fluidez do tempo, os conflitos e os sujeitos que estão presentes nas relações que ocorrem entre o local e o global. Isto é, Dematteis também está preocupado com as relações trans-escalares ou articulações territoriais, como denomina. Desta maneira, considera o tempo histórico, as relações multiescalares, as mudanças, os conflitos, a dominação e as tramas sociais em sua abordagem do território, que pode ser representado através de metáforas, o que revela uma abordagem múltipla, relacional e processual da dinâmica territorial.

Sobre a produção intelectual de Dematteis, ressaltamos, também, um texto de 2001, porque sintetiza sua argumentação para o entendimento do território e da territorialidade, através dos sistemas locais territoriais (Slot). Este deve ser, para além de instrumento de política territorial, uma forma analítica e, por isto, é construído a partir da realidade.

Desta forma, Dematteis (2001) propõe os seguintes componentes analíticos para o Slot: a) a rede local de sujeitos, que corresponde às interações entre indivíduos em um território local, onde há relações de proximidade física, reciprocidade etc. entre os sujeitos do local e de outros lugares, ocorrendo a construção de um ator coletivo; b) o milieu local, entendido como um conjunto de condições ambientais locais nas quais operam os sujeitos coletiva e historicamente; c) a relação da rede local com o milieu local e com o ecossistema, de forma tanto cognitiva (simbólica) quanto material. Há interações entre os domínios do social e do ambiente; d) a relação interativa da rede local com redes extra-locais, em distintas escalas: regional, nacional e global. Há influência mútua entre o local e o global.

Assim cada Slot, para Giuseppe Dematteis, tem aspectos ambientais e uma construção social histórica, tanto econômica quanto cultural e política, processual e relacional, na qual se dá uma organização no sentido da coesão e da projeção do 
futuro. O território e a territorialidade são produtos do entrelaçamento entre os sujeitos de cada lugar, destes com o ambiente e destes com indivíduos de outros lugares, efetivando tramas transescalares entre diferentes níveis territoriais. $\mathrm{O}$ território é uma construção coletiva e é multidimensional, com múltiplas territorialidades interagidas (poderes, comportamentos, ações), o que é ratificado por Governa (2001).

E, como há uma preocupação com a projeção, é importante que cada Slot tenha capacidade de autorepresentar-se e autoprojetar-se, sendo o estudo um meio para a conquista desta auto-organização. Daí a territorialidade ativa propugnada a partir de aspectos da abordagem de Raffestin (1980/81), como forma de desenvolvimento e conquista de autonomia. Isto significa que, optar por uma geografia da territorialidade, para Dematteis, implica numa mudança de paradigma de abordagem e de atuação na vida social, através de projetos de desenvolvimento local, o que caracteriza a chamada geografia democrática, há vários anos em evidência na Itália.

\section{A proposta humanística de Angelo Turco}

Angelo Turco é outro geógrafo italiano que tem insistido na abordagem territorial, pelo menos, desde o início dos anos 1980. Em uma de suas principais obras (1988), propõe a análise territorial de acordo com a categoria geográfica da complexidade, centrada no agir social coletivo do homo geographicus:

Entendemos a Geografia como a forma territorial da ação social. $O$ espaço é uma extensão da superfície terrestre dotada de atributos físicos e denominamos território um espaço no qual se exercita um trabalho humano; o processo através do qual o território se constitui é a territorialização (1988:15).

Já no início de sua obra, deixa clara sua compreensão do território e do espaço geográfico com base em Raffestin (1980/81), entendendo este último como substrato ou matéria-prima para a ação social que, coletivamente, produz o território. Angelo Turco tem outras referências, gerais e mais específicas, que subsidiam a elaboração de sua argumentação, como M. Foucault, N. Luhmann, E. Morin, P. Claval, Yi-Fu Tuan, G. Deleuze, G. Dematteis e H. Lefebvre, efetivando uma abordagem do território eminentemente humanística. Esta é sua ênfase, mesmo baseando-se em conceitos centrais da abordagem de Claude Raffestin.

No decorrer de sua obra, sinaliza para uma abordagem múltipla do território e da territorialização, na qual há uma centralidade na importância das relações de poder e nos dispositivos simbólicos de controle societal. O homem, ser biológico ê 
social, interage com outros homens e complexifica ou não sua vida, especialmente através de estratégias de poder. Isto é, propõe uma abordagem relacional do território.

No entendimento de Turco (1988), o homem produz e usa o território socialmente. $\mathrm{O}$ agir social é um agir territorial que constrói o território, marcando-o, sendo que este é também condição do jogo e da reprodução social. Assim, o território, em sua abordagem, é produto e condição de processos sociais, e propõe três categorias para ordenar as ações do homem: a) denominação; b) reificação e, c) estruturação. O território é um espaço, no dizer de Turco (1988), que contém atividades denominativas e/ou reificantes e/ou estruturantes. As denominativas, sucintamente, dizem respeito à atribuição de nomes aos lugares; as reificantes correspondem à intervenção estruturante, organizativa e transformativa, e a estruturação, à apropriação e controle do território.

Detalhando, conforme Turco (1988), estas categorias estão inter-relacionadas e substantivam o processo de territorialização. A denominação, para além da designação de nomes, significa controle simbólico realizado através da codificação, como aqui/lá, perto/longe, muito/pouco etc.. A reificação significa um controle prático, exercido através de construções (formas visíveis) e usos do território (regras, normas). Há transformação do ambiente natural em construído, socialmente: "A denominação dá conta de um modelamento intelectual e a reificação exprime um modelamento material" (TURCO, 1988:96). A estruturação do território, complexificada, corresponde a um dispositivo de controle, especialmente político, e é substantivada por nós, redes e malhas, justamente como argumentara Raffestin (1980/81). A territorialização corresponde a um processo de complexificação que ocorre sobre o espaço com componentes sistêmicos e relações sociais (tramas), isto é, um cenário plural que deve ser compreendido contemplando-se uma pluralidade escalar. Uma complexificação centrada no agir social e territorial, em que há o controle social (simbólico) e prático; tradições, mitos, religiões; ideologias; comportamentos, enfim, a territorialização.

No entanto, apesar dessas contribuições importantes para os avanços efetivados na abordagem territorial durante a década de 1980, nota-se alguns limites nas proposições de Angelo Turco, tais como o não aprofundamento da compreensão do tempo histórico, da natureza exterior ao homem como componente do território e das permanências e da transescalaridade, que estão subjacentes em sua proposta e são fundamentais para uma compreensão coerente da complexidade inerente à dinâmica territorial construída histórica e geograficamente. Ao mesmo tempo, Angelo Turco, nesta obra, não supera a dicotomia espaço-território, entendendo o primeiro como anterior, suporte e base da socialização e da territorialização. 


$$
\text { - }
$$


$\mathrm{Na}$ argumentação de Turri (2002), há elementos claros do método dialético, compreendendo o território como produto histórico, de mudanças e permanências; como projeção espacial bidimensional em um ambiente no qual se desenvolve uma sociedade. É uma apropriação social do ambiente; é o ambiente construído, em que há múltiplas variáveis e relações recíprocas e unitárias. O homem age no território, espaço (natural e social) de seu habitar, produzir, viver (objetiva e subjetivamente).

Turri identifica um território construído pela natureza, pelas forças físicas e um território historicizado, produzido pelo homem. O território é chão, formas espaciais, relações sociais e significados, produto de ações históricas (longa duração) que se concretizam em momentos distintos e superpostos. Há, assim, na abordagem territorial de Turri (2002), identidade e/ou enraizamento e conexões nos níveis nacional e internacional (relações internas e externas a cada lugar); heterogeneidade e unidade, natureza e sociedade.

Desta forma, a periodização é central na proposta de abordagem de Eugenio Turri, que contempla o presente como ponto de partida e a processualidade histórica como explicação da dinâmica social e natural. Evidencia a necessidade de se registrar as mudanças que ocorrem nas relações de produção, nos meios de produção e nos modos de uso do território.

Nesse sentido, para Turri (2002), um território pode ser campeão, laboratório ou problema. No primeiro, acontece a escolha de uma pequena área, lugar, para ser estudado; no segundo, além deste detalhamento, pode haver a resolução de problemas teóricos em virtude de um banco de dados e há uma vivência no e com $o$ território, possibilitando o planejamento deste; já no terceiro há o re-ordenamento, a re-configuração, superando a realidade local. São estágios que podem envolver a pesquisa científica com o envolvimento do pesquisador com os sujeitos que estão sendo estudados num determinado território. De modo geral, Eugenio Turri subsidia sua argumentação múltipla, relacional e processual em obras de geógrafos como M. Quaini, P. Claval, P. George, V. Vagaggini e Giuseppe Dematteis. Sobre o território, entre as obras que estamos aqui apresentando, a única que consta como referência é a de Dematteis (1995).

\section{Construindo uma abordagem (i)material do território}

Como temos afirmado desde 1996 e, principalmente, a partir de 2000, com base tanto em estudos empíricos como em reflexões teórico-metodológicas, como estas que aqui desenvolvemos, sobretudo as de C. Raffestin, G. Dematteis e E. Turri, é fundamental entender o território e a territorialização como resultado e condição de um processo histórico, em que há relações socioespaciais em diferentes níveis escalares (trans-escalaridade). E este é o ponto de partida.

Espaço, tempo e território são conceitos e processos do real intimamente articulados. Não estão separados, mas são diferentes. O homem, em sociedades 
distintas, está (no), produz (o),é (o) e percebe o território, arranjando-se em tramas e relações sociais, que são (i)materiais, ou seja, econômicas, políticas, culturais e naturais ao mesmo tempo. No homem reside a síntese do social e do natural, como ser genérico, biológica e socialmente, e a síntese da objetividade e da subjetividade, do (i)material. Somos objetivos e subjetivos concomitantemente, ou seja, não somos e nem vivemos somente a matéria ou a idéia em movimento.

Diferentemente da compreensão de Raffestin (1980/81/93) sobre o espaço geográfico e de acordo com Souza (1995) sobre esta questão, não entendemos o espaço apenas como palco, receptor de ações, substrato. $\mathrm{O}$ espaço geográfico tem um valor de uso, um valor de troca e é elemento constituinte do território, também, política e simbolicamente. Espaço e território são processos indissociáveis de nossa vida cotidiana, como delineia Dematteis (1985). Este é outro elemento importante.

Outros aspectos que julgamos relevantes em estudos territoriais, que sintetizamos a partir de argumentações anteriores (SAQUET, 2000, 2001/2003, 2004, 2004a e 2005), são: a) a identificação e caracterização de mudanças/descontinuidades e permanências/continuidades (des-continuidades), considerando-se suas contradições e relações de poder nas dinâmicas econômica, política e cultural; b) a heterogeneidade, como tempos (temporalidades) e territórios (territorialidades) ou as múltiplas formas e relações, em interação; c) a identidade ou traços comuns; d) as articulações territoriais, em rede, como um único movimento e, e) componentes da natureza exterior ao homem, influenciando e sendo influenciados em processos territoriais.

Como sabemos, a natureza está na sociedade, como natureza (i)norgânica do homem, e a sociedade está na natureza através do homem como ser genérico. Numa relação similar, a dinâmica econômica está, na constituição do território, nos processos políticos e culturais, identitários, e estes estão ligados ao movimento mercantil. Na produção do território, idéia e matéria estão em unidade. Uma está na outra e são historicamente determinadas. Os arranjos e as relações entre os diferentes elementos e aspectos das dimensões da territorialização variam para cada lugar e momento e/ou período histórico.

Há relações e interações entre a cultura, a política, a ideologia e com os elementos do movimento de re-produção do capital. Há um movimento interno à própria ideologia, à política e à economia. Tanto os componentes materiais como o ideário têm conteúdos que se efetivam na relação. $\mathrm{E}$ isto não significa dizer que estão, necessariamente, separados: são distintos mas são unos no mundo da vida. A separação pode ser um mero recurso didático, no processo de abstração e compreensão de aspectos desta unidade.

Desta maneira, em cada relação espaço-tempo pode(m) predominar certa(s) dimensão(sões) social(is) da constituição do território. Por isto, é importante se contextualizar os processos territoriais em cada período e lugar, em constante movimento de des-continuidades; desigualdades e diferenças, envolvendo aspectos dos domínios natural e social. 
O território é natureza e sociedade: não há separação; é economia, política e cultura; edificações e relações sociais; des-continuidades; conexão e redes; domínio e subordinação; degradação e proteção ambiental, etc.. Em outras palavras, o território significa heterogeneidade e traços comuns; apropriação e dominação historicamente condicionadas; é produto e condição histórica e trans-escalar; com múltiplas variáveis, determinações, relações e unidade. É espaço de moradia, de produção, de serviços, de mobilidade, de des-organização, de arte, de sonhos, enfim, de vida (objetiva e subjetivamente). O território é processual e relacional, (i)material, com diversidade e unidade, concomitantemente.

\section{PROPOSIÇÕES PARAESTUDOS TERRITORIAIS}

Resumo: Este texto focaliza alguns resultados de pesquisas realizadas nos últimos anos sobre as diferentes abordagens e concepções de território em Ciências Sociais, especialmente na Geografia, na Itália e no Brasil. Trabalha-se sobre proposições de C. Raffestin, G. Dematteis, A. Turco e E. Turri, precursores na re-elaboração da Geografia no pós-1960 e em estudos territoriais. No final, realiza-se algumas considerações teórico-metodológicas para uma abordagem (i)material do território, ainda em construção.

Palavras-chave: Geografia; Território; Método.

\section{PROPOSITIONS ON TERRITORIAL STUDIES}

Abstract: This text focus on some results of researches from the last years about different approaches and conceptions of territories in Social Sciences, specially in Geography, in Italy and Brazil. We work on assumptions from C. Raffestin, G. Dematteis, A. Turco and E. Turri, precursors in the re-elaboration of Geography after 60's and in territorial studies. In last considerations, we make some theoretic-methodological views for a(n) (i)material approach of territory, subject still under construction.

Keywords: Geography, Territory, Method.

\section{BIBLIOGRAFIA}

BAGNASCO, A. (1977). Tre Italie. La problematica territoriale dello sviluppo italiano. Bologna: Il Mulino.

BAGNASCO, A. (1988). La costruzione sociale del mercato. Bologna: Il Mulino. CORREAA, R. L. (1995). Espaço: um conceito-chave da Geografia. In: Castro, I. et al.(orgs.) Geografia: conceitos e temas. Rio Janeiro: Bertrand Brasil. p. 15-47.

DEMATTEIS, G. (1963). L'organizzazione del territorio nelle utopie sociali di T. Moro, T. Campanella, F. Bacone, Revista Geografica Italiana, LXX, p. 395-442.

DEMATTEIS, G. (1970). "Rivoluzione quantitativa" e nuova geografia. Lab. De Geografia Economica, n. 5, Università Degli Studi di Torino, Torino. 
(1985). Le metafore della Terra. La geografia umana tra mito e scienza. Milano: Feltrinelli.

(1995). Progetto implicito. Il contributo della geografia umana alle scienze del territorio. Milano: Franco Angeli.

(2001). Per uma geografia della territorialità attiva e dei valori territoriali. In: BONORA, Paola. Slot, quaderno 1. Bologna: Baskerville, p. 11-30.

GOVERNA, F. (2001) Il territorio come soggetto collettivo? Comunità, attori,territorialità. In: BONORA, Paola. Slot, cuaderno 1. Bologna: Baskerville, p. 31-46.

GOTTMANN, J. (1947). De la méthode d'analyse en géographie humaine, Bulletin de la Societé de Géographie, Paris, n.301, p.1-12.

(1973). The significance of territory. Charlottesville: University Press of Virginia.

GRAMSCI, A. (2002). Cadernos do Cárcere, vol. 3. RJ: Civilização Brasileira.

HAESBAERT, R. (1995). Desterritorialização: entre as redes e os aglomerados de exclusão. In: CASTRO, Iná et. al. (Orgs.). Geografia: Conceitos e Temas. Rio de Janeiro: Bertrand Brasil, p. 165-206.

(1997). Des-territorialização e identidade: a rede "gaúcha" no Nordeste. Niterói: EdUFF.

(2002). Concepções de território para entender a desterritorialização. Rio de Janeiro: Programa de Pós-Graduação em Geografia/UFF.

(2004). O mito da desterritorialização. Rio de Janeiro: Bertrand Brasil.

HAESBAERT, R. (2004a). Des-caminhos e perspectivas do território. In: RIBAS, Alexandre; SPOSITO, Eliseu e SAQUET, Marcos. Território e desenvolvimento: diferentes abordagens. Francisco Beltrão (PR): UNIOESTE, p.87-119.

IANNI, O. (1992). A sociedade global. RJ: Civilização Brasileira.

MARX, K.; ENGELS, F. (1998). La concezione materialistica della storia. Roma: Editori Riuniti.

RAFFESTIN, C. (1980). Pour une géographie du puvoir. Paris: Litec. (1981). Per una geografia del potere. Milano: Unicopli.

(1984). Territorializzazione, deterritorializzazione, riterritorializzazione e informazione. In: TURCO, Angelo. Regione e regionalizzazione. Milano: Franco Angeli. p.69-82.

(1993). Por uma geografia do Poder. SP: Ática.

RAFFESTIN, C. e GUICHONNET, P. (1974). Géographie des frontiers. Paris: Universitaires de France.

SANTOS, M. (1988). Metamorfoses do espaço habitado. SP: Hucitec. SAQUET, M. (2002/1996). Colonização italiana e agricultura familiar. Porto Alegre: EST Edições. 
(2000). O tempo, o espaço e o território. In: Souza, E.; Souza, A. (Orgs.). Paisagem, território, região: em busca da identidade. Cascavel, p. 103-114.

(2003/2001). Os tempos e os territórios da colonização italiana. Porto Alegre: EST Edições.

(2004). O território: diferentes interpretações na literatura italiana. In: SPOSITO, Eliseu; SAQUET, Marcos; RIBAS, Alexandre. (Org.). Território $e$ desenvolvimento: diferentes abordagens: Francisco Beltrão: EDUNIOESTE, p.121-147.

SAQUET, M. (2004a). A abordagem territorial: considerações sobre a dialética do pensamento e do território, Anais do I Seminário Nacional sobre Múltiplas Territorialidades, ULBRA/UFRGS, Canoas.

(2005). A relação espaço-tempo e a apreensão do movimento em estudos territoriais, Anais do X Encontro de Geógrafos da América Latina, USP, São Paulo, p. 125-135.

(2005a). Território e identidade entre italianos e seus descendentes no sul do Brasil, Anais do X Encontro de Geógrafos da América Latina, USP, São Paulo. p.197-211.

(2005b). Entender a produção do espaço geográfico para compreender o território. In: Sposito, Eliseu Savério. (Org.). Produção do espaço e redefinições regionais: a construção de uma temática. Presidente Prudente: FCT/UNESP/GAsPERR, p. 35-51.

(2006). Campo-território: considerações teórico-metodológicas, Revista Campo-Território, n.1, v.1, Uberlândia.

SOJA, E. (1971). The political organization of space. Washington: D. C.; Association of American Geographers.

SOUZA, M. L. (1995). O território: sobre espaço e poder, autonomia e desenvolvimento. In: CASTRO, Iná et. al. (Orgs.). Geografia: Conceitos e Temas. RJ: Bertrand Brasil, p. 77-116.

TURCO, A. (1988). Verso uma teoria geografica della complessità. Milano: Edizioni Unicopli.

TURRI, E. (2002). La conoscenza del territorio. Metodologia per un'analise storico-geografica. Venezia: Marsilio.

VAGAGGINI, V. e DEMATTEIS, G. (1976). I metodi analitici della geografia. Firenze: La Nuova Italia. 